\title{
¿Es posible programar temporalmente la ejecución de las obras derivadas de las licencias de edificación?
}

\author{
Avelino Blasco Esteve \\ Catedrático de Derecho Administrativo \\ Universitat de les Illes Balears
}

Sumario: I. INTRODUCCIÓN. II. ANÁLISIS DE LAS MEDIDAS QUE SE PRETENDEN ADOPTAR POR LOS AYUNTAMIENTOS DE CALVIÁ E IBIZA. III. FUNDAMENTACIÓN JURÍDICA DE LAS MEDIDAS INTRODUCIDAS POR LA MODIFICACIÓN PRETENDIDA. 1. La remisión de la Ley del Suelo a los planes de urbanismo. Capacidad de éstos para fijar límites a las facultades del derecho de propiedad y para establecer deberes urbanísticos. 2. La Ley del Suelo de 1998. Remisión al planeamiento para la fijación del plazo para edificar. 3. La Ley de Disciplina Urbanística de la CAIB (LDU).. 4. Sobre el carácter reglado de las licencias y el principio de seguridad jurídica. 5. La programación de la actividad urbanística. IV. CONCLUSIÓN

\section{INTRODUCCIÓN}

Los Ayuntamientos de Calviá e Ibiza (Illes Balears) pretenden efectuar una modificación puntual de su Plan General de Ordenación Urbana, a fin de habilitar normativamente la posibilidad de programar la ejecución de las licencias de edificación de uso residencial o turístico en el suelo urbano del Municipio. La motivación de la modificación estriba en dotar al Municipio de los medios legales para hacer frente a la avalancha que se está produciendo en los últimos tiempos de solicitudes de licencias en suelo urbano y urbanizable para usos residenciales y turísticos.

\section{ANÁLISIS DE LAS MEDIDAS QUE SE PRETENDEN ADOPTAR POR LOS AYUNTAMIENTOS DE CALVIÁ E IBIZA}

A) Conviene ante todo describir con precisión cuáles son las medidas que se pretenden adoptar por los Ayuntamientos de Calviá ${ }^{1}$ e Ibiza.

\footnotetext{
1 En el caso de Calviá, el texto de la propuesta de modificación del PGOU era el siguiente:

«Art. 2.07. Programación temporal de la ejecución de licencias.

1. Al otorgar las licencias de edificación relativas a edificios de uso residencial o turístico en suelo urbano, el Ayuntamiento de Calviá podrá programar la efectiva ejecución de las obras derivadas
} 
Entrando en el tema hay que decir que las medidas que se proyecta implantar mediante la modificación del PGOU pretenden ante todo habilitar normativamente a la Administración municipal para que pueda programar en el tiempo la ejecución de las obras derivadas de las licencias que se concedan para uso residencial o turístico en suelo urbano, dado que son las peticiones de este tipo de licencias las que se han «desbordado» en los años anteriores y en lo que va de 2001 , creando graves problemas en cuanto al desarrollo sostenible del municipio ${ }^{2}$.

de dicha licencia de manera temporal sucesiva, estableciendo el periodo temporal en el que deberán realizarse las obras. A tal efecto, la licencia señalará:

a) el día antes del cual no podrán iniciarse las obras (plazo mínimo para iniciar las obras);

b) el dia después del cual no podrán iniciarse las obras (plazo máximo para iniciar las obras);

c) el día después del cual no podrán acabarse las obras (plazo máximo para terminar las obras).

2. Se exceptúan de lo previsto en el apartado anterior las licencias en suelo urbano relativas a:

- edificaciones que sustituyan otra de igual uso derribada anteriormente;

— edificaciones de uso no residencial o turistico;

- edificaciones de viviendas acogidas a los regímenes de protección oficial en sus diversas modalidades general, especial o autonómica, promovidas por particulares o entidades públicas;

- rehabilitación o reforma de edificaciones de uso residencial plurifamiliar o de uso turístico, siempre que ello no suponga la ampliación del número de plazas existentes en las edificaciones a rehabilitar o reformar

- rehabilitación o ampliación de edificaciones de uso residencial unifamiliar.

- los núcleos urbanos de Calvià Vila y Es Capdellà, dadas sus caracteristicas específicas.

3. En las licencias a que se refiere el apartado $1 .^{\circ}$ de este artículo, el número máximo de plazas tanto residenciales como turisticas que se podrán autorizar cada año natural es el siguiente:

- 500 plazas para las edificaciones de uso turístico. A tal efecto, sólo se computará la diferencia entre el número de plazas nuevas autorizadas y el número de plazas que se den de baja, de acuerdo con la legislación turistica y las presentes normas;

- 850 plazas para las edificaciones de uso residencial, de las cuales 530 son para las edificaciones de uso plurifamiliar, equivalente a 166 viviendas, y 320 plazas para las edificaciones de uso familiar aislado, equivalentes a 100 viviendas.

A efectos de cómputo se considera que, en las edificaciones de uso residencial, cada vivienda comporta un total de 3,2 plazas.

Las plazas que eventualmente no se adjudiquen en cualquiera de estos grupos o subgrupos en un mismo año no podrán acrecer a ningún otro, aunque sí que serán acumulables respecto de las plazas autorizadas en el año siguiente para el mismo grupo o subgrupo.

4. El criterio para establecer el orden de ejecución de las licencias a que se refiere el apartado $1 .^{\circ} \mathrm{y}$ de realización material de las obras correspondientes será exclusivamente, para cada grupo o subgrupo, el de la fecha de presentación de la solicitud de la licencia junto con la documentación preceptivamente exigible, de conformidad con lo dispuesto en el artículo 6.04 de estas Normas Urbanísticas.

2 En concreto, la población de Calviá había crecido de forma espectacular en los últimos años, pasando de una población censada de 21.000 habitantes en 1991, a 31.200 en 1995 y a una población 
Pero, ¿qué es "programar en el tiempo la ejecución de las obras»? Pues, sin duda, se trata de fijar, de modo vinculante para los administrados, la época o período de tiempo en el que deberán realizarse las obras derivadas de dichas licencias. Esta posibilidad ya está prevista en la legislación urbanística actual, como luego veremos (concretamente en el art. 14 de la Ley del Suelo de 1998 y en el art. 8.1 de la Ley de Disciplina Urbanística de la CAIB), pero hasta ahora sólo había sido utilizada para establecer un plazo máximo para iniciar las obras y otro para acabarlas, permitiendo con ello que aquéllas empiecen inmediatamente después de otorgada la licencia, con lo que el «ritmo» de la actividad edificatoria ha sido hasta ahora libremente decidido por los promotores particulares: como es notorio, una vez que la parcela respectiva tiene la condición de solar, el propietario puede solicitar la licencia sin necesidad de esperar plazo alguno $\mathrm{y}$, concedida la licencia, puede igualmente empezar las obras sin más demora.

Esto significa que el sistema actual, que pivota exclusivamente alrededor de los dos plazos máximos señalados (plazo para iniciar las obras y plazo para terminarlas), se ha preocupado mucho y con efectos contundentes del momento final hasta el que los particulares deben ejercitar necesariamente sus derechos, transcurrido el cual puede declararse nada menos que la caducidad de la licencia si tales derechos no se han puesto en práctica; pero, en cambio, el sistema no se ha ocupado para nada del momento inicial en el que han de hacerlo, momento que ha sido libremente abandonado a la iniciativa privada.

Este distinto tratamiento jurídico del dies a quo en el que pueden iniciarse las obras, por una parte, y del dies ad quem en el que deben iniciarse o del dies ad quem en el que deben acabarse, por otra, no deja de ser sorprendente. Como hemos dicho, la vulneración de los plazos máximos de inicio o de terminación de las obras produce consecuencias devastadoras para el título jurídico habilitante de la actividad edificatoria (la licencia): nada menos que su caducidad o extinción jurídica, con lo que los derechos reconocidos en la licencia ya no pueden ser ejercitados, debiendo solicitarse una nueva licencia en caso de que todavía sea posible. Frente a estos rotundos efectos por el incumplimiento de los plazos máximos, no se ha avanzado

de más de 40.000 en el año 2000. Además, durante cada año son más de 1.600 .000 turistas los que pasan sus vacaciones en Calvià, con una estancia media de unos 12 dias.

Cabe resaltar también la fuerte progresión del número de licencias que pasa de 159 expedientes en 1993 a 571 en 1997 y a 637 en 1999. De forma incluso más espectacular, cabe indicar que el Presupuesto de obras incluidas en las solicitudes de licencias ha crecido desde los 1.708 millones de pesetas en 1993 a 25.443 millones en 1997 y a casi 27.000 millones en 1998. 
en la praxis urbanística en la fijación y programación de plazos mínimos para las obras, a fin de que las obras correspondientes a las diferentes licencias vayan ejecutándose de una manera sucesiva o escalonada, de modo que sea compatible con el desarrollo sostenible de la presión humana sobre el territorio. Más adelante volveremos sobre este punto.

B) Con la modificación del PGOU que se proponen los Ayuntamientos de Calviá e Ibiza, se intenta avanzar un paso más en la dirección expuesta de programar las obras, permitiendo en concreto que la licencia pueda establecer razonadamente cuál es el período temporal en el que deberán iniciarse las obras, fijando a tal efecto no sólo un plazo máximo para iniciarlas sino también un plazo mínimo, en el cual no pueden empezar las obras hasta que llegue el momento señalado por la Administración.

De esta manera, la licencia podrá señalar los tres momentos a los que hay que atender obligatoriamente para la finalidad prevista. Estos momentos son en concreto:

- la fecha o momento inicial en el podrán empezarse las obras de edificación (plazo mínimo para iniciar las obras), de manera que las obras no podrán comenzar válidamente hasta que llegue ese momento;

- la fecha o momento final en el que podrán empezarse las obras (plazo máximo para iniciar las obras), transcurrido el cual se podrá declarar la caducidad de la licencia;

- el plazo máximo para acabar las obras, transcurrido el cual también se podrá declarar la caducidad de la licencia.

Este sistema de programación vinculante supone así abandonar la tradicional regla de libertad en cuanto al momento de iniciar las obras, las cuales podían ser ejecutadas de modo inmediato a su expedición por el titular de la licencia, estableciendo en su lugar una ejecución sucesiva o gradual de las diferentes licencias que se concedan en un período determinado, para hacer compatible el proceso edificatorio con un desarrollo sostenible en función de los recursos disponibles.

C) La posibilidad de programar la ejecución de las licencias debe acompañarse de modo inevitable de la fijación en la misma norma de unos topes o máximos cuantitativos en cuanto al número de licencias a ejecutar anualmente, lo que significa que las licencias que rebasen esos parámetros máximos, aunque sean concedidas, no podrán ser ejecutadas 
¿ES POSIBLE PROGRAMAR TEMPORALMENTE LA EJECUCIÓN DE LAS OBRAS...

inmediatamente después de su otorgamiento sino cuando razonadamente programe la Administración.

Por otra parte, el número total de plazas autorizables cada año (tanto residenciales como turísticas) que se fije en la modificación habrá de distribuirse en la norma de una manera que se considere razonable y equitativa entre los distintos usos posibles: usos residenciales (distinguiendo el plurifamiliar del unifamiliar), usos turísticos, etc., tal como hace, por ejemplo, la propuesta del Ayuntamiento de Calviá.

$\mathrm{Al}$ establecer topes anuales cuantitativos, es también obligado que la modificación incorpore los criterios en base a los cuales la Administración establezca el orden de ejecución de las licencias que otorgue, cuando éstas rebasen el tope fijado para cada año. A estos efectos, la modificación debería decantarse por un criterio absolutamente objetivo: el de la fecha de presentación de la solicitud de la licencia junto con la documentación completa que la ha de acompañar. Como en tantas otras ocasiones en que el número de autorizaciones administrativas que se puede otorgar es limitado, se debe conceder una prioridad a aquellas personas que han solicitado antes la autorización necesaria para el ejercicio de sus derechos, en aplicación del principio jurídico clásico prior tempore, potior iure.

D) Como reflexión general, debemos reparar en que las medidas que se pretenden implantar con la modificación proyectada no suponen merma o reducción en lo que respecta al contenido de los derechos de aprovechamiento urbanístico de los particulares: el quantum de estos derechos continúa siendo exactamente el mismo, ya que la edificabilidad (usos, intensidades, tipologías) que les atribuye el Plan no varía en absoluto. No hay, por ello, reducción de aprovechamiento, que implique o pueda implicar responsabilidad patrimonial de la Administración, a tenor de la Ley sobre Régimen del Suelo y Valoraciones de 1998 (Ley 6/1998, de 13 de abril).

Lo único que se altera en realidad es el ritmo temporal de ejercicio del derecho a edificar por parte de los titulares de la licencia: hasta ahora sólo se establecía un plazo máximo para iniciar las obras y otro para acabarlas, pero las obras podían iniciarse inmediatamente después de otorgada la licencia. Con la modificación, por contra, la Administración podrá establecer además un plazo mínimo antes de iniciar las obras, en aras de la programación a que hemos aludido.

Por otra parte, la licencia que se otorgue en estas condiciones, es decir, con una programación vinculante para su titular, no deja de ser un acto 
declarativo de derechos que consolida la situación jurídica de quien la obtiene, ya que patrimonializa de modo definitivo la facultad de edificar reconocida en ella. Con la programación, no hay pues un retraso o demora en el otorgamiento de la licencia, es decir, en el reconocimiento por la Administración de la facultad de edificar (ya que ello se efectúa mediante la concesión de la licencia), sino sólo una temporalización de su ejercicio, lo cual presupone de modo claro la previa adquisición de la facultad, porque sólo se pueden ejercer aquellos derechos o facultades que ya se tienen.

Además, este tipo de licencias constituyen actos favorables a los particulares que la Administración deberá respetar en todo caso y que no podrá desconocer. En cuanto negocio jurídico ya existente y perfeccionado, la licencia así otorgada no podrá ser revocada por la Administración por motivos de oportunidad o libre apreciación. En efecto, el principio general consagrado en el artículo 105.1 de la Ley de Procedimiento Administrativo Común es el de la irrevocabilidad de los actos administrativos declarativos de derechos: como es sabido, este precepto señala que «las Administraciones públicas podrán revocar en cualquier momento sus actos de gravamen o desfavorables....», lo que significa a sensu contrario que no es legalmente posible la revocación de los actos favorables o declarativos de derechos, principio aplicable a las licencias urbanísticas. El principio sólo se excepciona cuando una norma con rango legal establece lo contrario, posibilitando la excepción. Éste es el caso, por ejemplo, del artículo 42.2 de la Ley sobre Régimen del Suelo y Valoraciones, que permite la revocación de la licencia cuando se produce una modificación o revisión del Plan, si aquélla es disconforme con éste y las obras ya han comenzado: en este caso, la revocación es legalmente posible, pero siempre con indemnización de todos los daños y perjuicios causados por la misma.

Pues bien, este régimen general sobre revocación o no de las licencias urbanísticas será perfectamente aplicable a las licencias que hayan sido objeto de programación por los Ayuntamientos de Calviá e Ibiza, durante el período en el que no se puedan comenzar las obras (el «plazo mínimo de inicio» de obras). 
¿ES POSIBLE PROGRAMAR TEMPORALMENTE LA EJECUCIÓN DE LAS OBRAS...

\section{FUNDAMENTACIÓN JURÍDICA DE LAS MEDIDAS INTRODUCIDAS POR LA MODIFICACIÓN PRETENDIDA}

El fundamento jurídico de la medida que se pretende adoptar se encuentra en diversos preceptos de la legislación urbanística en vigor, que paso a examinar a continuación.

\section{La remisión de la Ley del Suelo a los planes de urbanismo. Capacidad de éstos para fijar límites a las facultades del derecho de propiedad y para establecer deberes urbanísticos}

A) Con carácter general, el problema que se plantea con la modificación pretendida por los Ayuntamientos de Calviá e Ibiza es el de si los planes urbanísticos pueden fijar límites a las facultades derivadas del derecho de propiedad, así como establecer deberes para los propietarios, cuando esos límites y esos deberes no estén expresamente previstos por la Ley. Ya veremos después que la apoyatura legal de la modificación pretendida descansa concretamente en varios preceptos de la LS/98 y de la Ley de Disciplina Urbanística balear de 1990 (LDU), pero, con independencia de ello, creo que es necesario efectuar previamente la reflexión que se acaba de proponer, o sea, averiguar hasta qué punto los Planes pueden fijar límites y establecer deberes urbanísticos.

Entrando en el tema, el punto de partida está en el artículo 2.1 de la LS/98, que remite a los planes urbanísticos la fijación de límites y el establecimiento de deberes a las facultades urbanísticas que deriven del derecho de propiedad («Las facultades urbanísticas del derecho de propiedad se ejercerán siempre dentro de los límites y con el cumplimiento de los deberes establecidos en las leyes o, en virtud de ellas, por el planeamiento.....»). Este precepto viene a recoger una regla que ya estaba en la Ley del Suelo de 1956, que luego pasó al artículo 76 de la Ley del Suelo de 1976 y que ahora se halla en el frontispicio de la LS/98.

Pues bien, ante este precepto, la pregunta que hay que hacerse es hasta dónde llega la virtualidad de esta remisión a los planes en cuanto a la fijación de límites y al establecimiento de deberes.

B) Para resolver el problema planteado, debemos empezar recordando las modulaciones de la reserva legal en materia de propiedad y, en especial, de la propiedad inmueble. Como es sabido, el artículo 53.1 de la Constitución establece una genérica reserva de ley para la regulación del 
ejercicio de los derechos y libertades reconocidos en el Capítulo II del Título I - entre los cuales se encuentra el derecho de propiedad - , cuando dice que «los derechos y libertades reconocidos en el Capítulo II del presente Título vinculan a todos los poderes públicos. Sólo por ley... podrá regularse el ejercicio de tales derechos y libertades...». Ahora bien, en materia de propiedad, el artículo 33.2 de la misma Constitución vuelve a efectuar una remisión a las leyes que parece más flexible que la del artículo 53.1, al disponer que «la función social de estos derechos (la propiedad privada y la herencia) delimitará su contenido, de acuerdo con las leyes». De este modo la tajante expresión «sólo por ley» del artículo 53.1 se convierte en la más flexible «de acuerdo con las leyes» del artículo 33.2 .

Estas diferencias de enunciado han sido interpretadas por la mejor doctrina como una flexibilización de la genérica reserva de ley del artículo $53 \mathrm{CE}$ en materia del derecho de propiedad. Así, L. PAREJO ALFONSO ya señaló tempranamente ${ }^{3}$ que

«... esta discrepancia entre ambos preceptos (el 53.1 y el 33.2 CE) debe resolverse obviamente en una solución que armonice ambos mandatos, siempre que tal solución sea posible. Pues ha de tenerse en cuenta que el artículo 53.1 expresa una regla general e indiscriminada para todos los derechos fundamentales, sin atender a las características específicas de cada uno de ellos, y el artículo 33 contiene, por el contrario, una regla directamente formulada a la vista de las peculiaridades del derecho de propiedad, de forma que no se está ante preceptos con regulación discrepante de un supuesto idéntico. Por el contrario, se mueven en planos distintos y están en una relación del tipo generalidad-especialidad, lo que hace factible una interpretación coherente en el sentido señalado...

La naturaleza misma de la tarea propia de la ordenación territorial o urbanística exige de ésta la atención a las circunstancias concretas de cada territorio, en último extremo, de cada parcela; circunstancias que, además de variar en el espacio, varían también, y con relativa rapidez, en el tiempo. Esta crucial circunstancia otorga... una clara justificación material al artículo 33.2, en tanto que flexibiliza la reserva de ley; justificación que no puede dejarse de tener en cuenta a la hora de la interpretación sistemática de los preceptos constitucionales examinados...

Partiendo de esa justificación resulta relativamente sencillo encontrar la fórmula de equilibrio buscada. La Ley habrá de regular por sí misma, a fin de cumplir el artículo 53.1, todo cuanto sea susceptible de ser regulado a través de normas legales, caracterizadas por su generalidad, abstracción y vocación de permanencia. Alcanzado el punto en que la Ley razonablemente no pueda ir más allá, debe entenderse que cesa la exigencia... de la reserva material de Ley, abriendo el paso a la posibilidad de la colaboración de ésta con el Reglamento, tal como autoriza desde luego el artículo 33.2

\footnotetext{
${ }^{3}$ En su libro Régimen urbanistico de la propiedad y responsabilidad patrimonial de la Adminis-
} tración, IEAL, Madrid, 1982, pp. 34-36. 
¿ES POSIBLE PROGRAMAR TEMPORALMENTE LA EJECUCIÓN DE LAS OBRAS...

Pues bien, la vigente LS (de 1976) responde perfectamente a la solución alcanzada. Porque no se limita a servir de llave para la ocupación de la materia por el Reglamento (Plan). Antes al contrario, ella misma contiene prescripciones sustantivas de ordenación urbanística (en particular, establece un régimen urbanístico, siquiera básico pero muy preciso, del derecho de propiedad del suelo, apurando al máximo las posibilidades de normación general y abstracta de la materia. Sólo agotadas esas posibilidades utiliza la Ley la técnica delegativa de la remisión a normas de inferior rango».

Pues bien, la jurisprudencia ha seguido esta interpretación, considerando que la reserva de ley del artículo 33.2 CE es más flexible que la del artículo 53.1 CE. Como dicen las Sentencias del Tribunal Supremo de 2.02.87, 17.06.89, 28.11.90 y 12.02.91, «la reserva de ley en materia de propiedad ha sido flexibilizada por el artículo 33.2 de la Constitución que indica que la regulación de esta figura ha de llevarse a cabo "de acuerdo con las leyes": no sólo, pues, la Ley sino también los productos normativos de la Administración y más concretamente los Planes, pueden contribuir a determinar el contenido del derecho de propiedad y más específicamente las facultades urbanísticas que lo integran. Resulta así clara la constitucionalidad de que el planeamiento venga a trazar el contenido último del derecho de propiedad en virtud del artículo 76 del Texto Refundido de 1976».

C) En el plano específicamente urbanístico, la remisión de la Ley del Suelo a los Planes ha sido también interpretada por la doctrina y la jurisprudencia como una remisión específica y más flexible que la remisión general de la ley al reglamento. En efecto, en el marco general de relaciones entre ambos tipos de normas no es admisible en principio otra norma reglamentaria que la de mero desarrollo de la ley (los llamados «reglamentos ejecutivos»)). Sin embargo, en el caso del urbanismo, el Plan hace algo más que desarrollar la ley, ya que detalla o precisa para cada parcela concreta cual es el contenido exacto del derecho de propiedad inmueble. Esta particularidad de los Planes como normas reglamentarias la ha puesto de relieve con precisión J. M. ${ }^{a}$ BAÑo LEÓN ${ }^{4}$, que trata específicamente de la remisión de la Ley del Suelo a los planes de urbanismo:

"Cuando, como es el caso del urbanismo, la ley remite al Plan la determinación de elementos decisivos en la configuración de la propiedad en un municipio, ciertamente no está «desarrollando» la ley. El Plan no puede contrariar las determinaciones legales o los estándares mínimos, pero su labor no se limita a desarrollar un programa prefijado por la ley. Por el contrario, el Plan, y esto es lo característico de esta figura, basada en la fijación de objetivos concretos y medios para

\footnotetext{
${ }^{4}$ En su libro Los límites constitucionales de la potestad reglamentaria (Ed. Civitas, Madrid, 1991, p. 138).
} 
llevarlos a cabo, configura per se determinaciones urbanísticas fruto de la «política» propia de su autor. La Ley sirve al Plan más como norma marco en la que se fijan los límites que éste no puede sobrepasar que como una norma predeterminante de su contenido...... Pese a ello, no puede decirse que una norma, que en puridad remite la definición del estatuto de la propiedad a un instrumento de carácter reglamentario, viole la reserva de ley. La razón es que esta técnica es la única que puede permitir perfilar para cada situación concreta cuál es la mejor ordenación (políticamente) posible.

Por tanto, y de acuerdo plenamente con BAÑo LEÓN, podemos afirmar que el Plan de urbanismo no se limita a desarrollar la Ley del Suelo, sino que configura una política propia de su autor (la política urbanística), a través de la delimitación de los derechos de los particulares en cada zona y en cada parcela de cada Municipio, cosa que no podría hacer en absoluto la Ley: de este modo, la legitimación de la remisión legal al Plan se ha de buscar en la imposibilidad física y jurídica de que la ley fije el régimen aplicable a cada parcela de terreno y a cada Municipio en concreto.

De ahí que algunos autores consideren que los Planes no son propiamente «reglamentos ejecutivos» de las leyes, sino que son «reglamentos remitidos» o dictados por remisión, con un mayor margen o espacio normativo que aquéllos. Así lo entiende, por ejemplo, PÉREZ ANDRÉs ${ }^{5}$.

En conclusión, vemos cómo el Plan de urbanismo puede legítimamente delimitar el contenido del derecho de propiedad no sólo espacialmente (clasificando y calificando suelo), sino también temporalmente (programando en el tiempo el ejercicio de las facultades urbanísticas), tal como se hace en la modificación del PGOU que pretenden los Ayuntamientos de Calviá e Ibiza ${ }^{6}$.

\footnotetext{
${ }^{5}$ En «La limitación constitucional de la remisión legislativa al planeamiento», publicado en la $R e$ vista de Derecho Urbanistico, n. ${ }^{\circ} 146$, p. 79.

${ }^{6} \mathrm{Al}$ respecto del tema que tratamos, y con fecha 19 de abril de 2001, el Consell Consultiu de les Illes Balears ha emitido dictamen sobre la modificación que pretendía el Ayuntamiento de Calviá, considerando que la modificación pretendida no se ajusta a Derecho, aunque utilizando para ello como parámetro básico de comparación la Ley balear de Disciplina Urbanística y no la legislación general del suelo que acabamos de citar. En mi opinión, la LDU constituye sin duda un referente normativo importante en la solución del debate planteado, pero no es el único, ni mucho menos y, desde luego, no el principal, y el mayor error del dictamen citado es precisamente el de no tener en consideración esa legislación general del suelo.
}

En efecto, como se acaba de exponer con detalle, el problema de fondo que se plantea en el presente caso es el de si los planes urbanísticos pueden fijar límites a las facultades derivadas del derecho de propiedad, así como establecer deberes para los propietarios, cuando esos límites y esos deberes no estén expresamente previstos por la Ley. Y para resolver esta cuestión, la LDU balear es manifiestamente insuficiente, ya que tenemos que acudir de modo preciso a la legislación que con carácter general regula los derechos y deberes de los propietarios de suelo (la LS/98) y a la legislación, que regula las determinaciones del planeamiento urbanístico (el Texto Refundido de 1976 en la CAIB). 


\section{La Ley del Suelo de 1998. Remisión al planeamiento para la fijación del plazo para edificar}

A) Como hemos apuntado, la Ley estatal del Suelo de 1998 (LS/98) contiene varios preceptos absolutamente básicos para la resolución del tema que nos ocupa.

a) De entrada, la remisión que hace su artículo 2.1 a los planes urbanísticos para la fijación de límites y el establecimiento de deberes a las facultades urbanísticas que deriven del derecho de propiedad ${ }^{7}$.

b) También, el mandato que hace el artículo 4 a los poderes públicos para dirigir el proceso urbanístico ${ }^{8}$.

c) La remisión que hace el artículo 13 al planeamiento en la definición de los derechos de los propietarios de suelo urbano ${ }^{9}$.

d) El artículo 14.1 de la Ley señala que uno de los deberes de los propietarios de suelo urbano consolidado por la urbanización es el de «edificarlos (los solares) en plazo si se encontraran en ámbitos para los que así se haya establecido por el planeamiento y de conformidad con el mismo». De la misma manera, el artículo 14.2.f) dispone para los propietarios de suelo urbano sin urbanización consolidada el deber de «edificar los solares en el plazo que, en su caso, establezca el planeamiento».

e) La misma remisión hace el artículo 18.7 para los propietarios de suelo urbanizable ${ }^{10}$.

\footnotetext{
Éste es un punto clave, a mi juicio: si se trata de averiguar hasta dónde puede llegar legalmente un plan de urbanismo en la definición de deberes de los propietarios, no queda otro remedio que acudir a la normativa que regula con carácter general esos temas, normativa que trasciende con mucho la LDU balear, cuya perspectiva es la estricta de la disciplina urbanística, es decir, la de controlar que la ejecución del plan sea realizada correctamente y sin incumplimientos.
}

7 Art. 2.1 LS/98: «Las facultades urbanisticas del derecho de propiedad se ejercerán siempre dentro de los límites y con el cumplimiento de los deberes establecidos en las leyes o, en virtud de ellas, por el planeamiento..."

${ }^{8}$ Art. 4.1 LS/98: «Los propietarios deberán contribuir.... a la acción urbanística de los entes públicos, a los que corresponderá, en todo caso, la dirección del proceso, sin perjuicio de respetar la iniciativa de aquéllos.»

9 Art. 13 LS/98: «Los propietarios de suelo urbano tienen el derecho a completar la urbanización de los terrenos para que adquieran la condición de solares y a edificar éstos en las condiciones que en cada caso establezca la legislación urbanistica y el planeamiento.»

10 Art. 18 LS/98: «La transformación del suelo clasificado como urbanizable comportará para los propietarios del mismo los siguientes deberes:... 7. Edificar los solares en el plazo que, en su caso, establezca el planeamiento.» 
Pues bien, de todos estos preceptos se obtiene la conclusión meridiana de que existe un auténtico deber jurídico de los propietarios de edificar los solares en los plazos que establezca el planeamiento: es éste, por remisión de la ley, el que ha de fijar los plazos en que tendrá que hacerse efectivo ese deber, ya que la LS/98 no ha querido establecer por sí misma ningún plazo, a diferencia de lo que hacía el Texto Refundido de la Ley del Suelo de 1992.

Pues bien, al hacer esa remisión al planeamiento, la LS/98 no distingue entre plazos máximos o mínimos, sino que habla del «plazo» en abstracto. Este plazo ha sido entendido tradicionalmente como un plazo máximo para iniciar las obras y otro para acabarlas. Pero la remisión de la Ley no precisa que tenga que tratarse necesariamente de un plazo máximo, lo que permite a mi juicio que pueda tratarse también de un plazo mínimo (o, más en general, que se programe el período de tiempo en que debe cumplirse el deber de edificación, fijando al respecto los plazos mínimos y máximos que sean convenientes para ello). Si el planeamiento puede fijar plazos máximos para iniciar o acabar la edificación, ¿por qué motivo no va a poder señalar el período concreto en el que se deba edificar, incluyendo un plazo mínimo antes del inicio de las obras, a efectos de configurar una programación conjunta y gradual de toda la actividad edificatoria? No admitirlo así sería incongruente, a tenor del argumento maiore ad minus, ya que el incumplimiento de los plazos máximos produce efectos drásticos (la caducidad de la licencia) como ya vimos, mientras que el incumplimiento de plazos mínimos sería mucho menos trascendente, al consistir únicamente en la adopción de las medidas pertinentes contra obras que no se ajusten a las condiciones de la licencia (o sea, paralización de las obras e imposición de sanciones), pero en ningún caso llegarían a declarar su caducidad o extinción jurídica.

El sistema tradicional que se ha descrito de fijación sólo de plazos máximos supone en gran manera una renuncia a la idea de programación por parte de la Administración y, por ende, de dirección efectiva de los procesos urbanísticos por aquélla, desconociendo así uno de los principios de nuestro Derecho urbanístico, que ahora se plasma en el citado artículo 4.1 de la LS/98 («Los propietarios deberán contribuir, en los términos establecidos en las leyes, a la acción urbanística de los entes públicos, a los que corresponderá, en todo caso, la dirección del proceso, sin perjuicio de respetar la iniciativa de aquéllos»). Si en las licencias sólo se pudieran establecer plazos máximos (tanto para iniciar como para acabar las obras), esto supone que en la práctica —al menos en hipótesis— todas las posibles licencias que quedaran por conceder en un determinado munici- 
pio podrían ser solicitadas, otorgadas y ejecutadas simultáneamente, lo cual no deja de ser un despropósito, porque se agotaría en unos cuantos meses toda la capacidad de crecimiento del plan, prevista habitualmente para varios años: este resultado absurdo y descabellado, pero teóricamente posible, es a mi juicio uno de los argumentos más sólidos a favor de la legitimidad del nuevo sistema.

En conclusión, vemos que, según los artículos citados de la LS/98, es perfectamente posible que el planeamiento fije plazos para edificar en suelo urbano consolidado en los «ámbitos» que aquél establezca (ámbitos que pueden ser no sólo territoriales sino también materiales o para ciertos usos) y de conformidad con el propio Plan. En el caso que nos ocupa, los Ayuntamientos de Calviá e Ibiza pretenden precisamente establecer plazos en suelo urbano y urbanizable para edificaciones de uso residencial o turístico, es decir, para ciertos usos, dado que son éstos los que están provocando la avalancha de solicitudes de licencias a que nos referíamos al principio.

B) Algo parecido ocurre si acudimos a la legislación vigente en la CAIB en materia de planeamiento urbanístico, que es la Ley del Suelo de 1976 (LS/76). Ésta permite a la Administración «exigir a los propietarios que edifiquen en plazos determinados» [art. 3.4.c)]. Por otra parte, el artículo 26.1 del Reglamento de Planeamiento Urbanístico dice que el Plan General "señalará, para todo el suelo comprendido en su ámbito, los objetivos, directrices y estrategia de su desarrollo».

C) De todo lo anterior se extrae la conclusión de que existe una clara habilitación de la legislación del suelo para que los Planes (en especial, los Planes Generales) contengan determinaciones, si así lo estiman oportuno, respecto a los plazos de edificación.

Estos argumentos han sido ya recogidos en dos magníficas sentencias recientes y firmes de los dos Juzgados de lo Contencioso-Administrativo de Palma (Sentencia 41/2001 del Juzgado n. ${ }^{\circ} 1$ y Sentencia 56/2001 del Juzgado . $^{\circ} 2$ ). Para rebatir la presunta vulneración del límite temporal de 2 ó 3 años para la realización de las obras que establece el artículo $154 \mathrm{LS} / 76$ y la alegada vulneración del artículo 8.1 LDU que efectuaban los recurrentes - precepto al que luego nos referiremos-, las dos sentencias señalan lo siguiente:

«El artículo 14.f) de la Ley 6/98 establece que es un deber de los propietarios edificar los solares en el plazo que en su caso, establezca el planeamiento. Por lo tanto, esa remisión al planeamiento permite comprender no solamente el cumpli- 
miento del plazo edificativo que establecen los artículos 154 y 155 LS/76 sino que permite entender que esa obligación se hará conforme a todas las contingencias que prevea ese planeamiento, y puede ciertamente que las necesidades e intereses colectivos obliguen a una distribución racional y escalonada de la materialización de esas obras, todo ello tendente al hecho de evitar dentro de un término municipal, eminentemente turístico y residencial, el impacto ambiental y paisajístico de más de 500 licencias concedidas en un solo año, en el caso de que se estén ejecutando, sin contar las que se edifiquen y correspondan a años anteriores y las consecuencias de todo orden que ese crecimiento desmedido comporta en la satisfacción de los servicios por parte del Ayuntamiento (transporte, aguas, saneamiento, etc.). Ello no supone una vulneración normativa, pues lo que no podría contemplar el planeamiento es conceder un proceso de edificación superior a los dos o tres años, que es lo que expresamente se contempla en la ley, pero nada impide que se regule por el plan cuándo empezará a contar ese plazo constructivo, que es lo que precisamente esa modificación contempla.

La solución es ciertamente novedosa.... y no se comparte que ello suponga un ataque a los derechos de propiedad y disfrute de la vivienda, como expone el recurrente en su demanda. No se está limitando el derecho a edificar, sino lo que se está haciendo es una distribución gradual y en el tiempo de ese derecho. No se olvide que el ius aedificandi que posee todo propietario nazca una vez concedida la licencia, y por lo tanto está condicionado a la normativa del planeamiento y a las determinaciones urbanísticas en que quede clasificada y detallada su propiedad. Por lo tanto, si la limitación puede llegar a ser máxima y no constituye una vulneración jerárquica el que el planeamiento, normativa de carácter reglamentario, rebaje sustancialmente o hasta impida ese derecho, ni tampoco ello constituye una vulneración del derecho de propiedad (por todas, las STS de 2 de febrero de 1987), menos lo será si lo único que efectúa el plan es una graduación temporal de la materialización del derecho a edificar que se concede con la licencia, respetando el límite temporal del plazo de materialización de ese derecho que viene legalmente determinado en los artículos 154 y 155 LS/76.»

$\mathrm{El}$ argumento, como vemos, es impecable, y viene a coincidir con los razonamientos que aquí se han expuesto, basándose esencialmente en el artículo 14 de la Ley del Suelo de 1998 y haciendo una interpretación de la Ley de Disciplina Urbanística balear compatible o congruente con aquella ley básica. El argumento se remata con unas magníficas consideraciones de carácter general, que sólo me resta reproducir:

«Nadie cuestiona el hecho del carácter estatutario del derecho de propiedad que queda limitado en atención a lo que el interés público reclama. No en vano el artículo 76 de la Ley del Suelo de 1976 establece que «las facultades del derecho de propiedad se ejercerán dentro de los límites y con el cumplimiento de los deberes establecidos e esta Ley, o en virtud de la misma, por los Planes de Ordenación, con arreglo a la clasificación urbanística de los predios». Así viene también configurado ese derecho en la Constitución en su artículo 33.2, cuando dice que la función social del derecho de propiedad delimitará su contenido de acuerdo con las leyes. La exigencia de un desarrollo racional de crecimiento de las ciudades, que es de todos y no sólo de los propietarios de los terrenos, pasa desde luego por el sometimiento del derecho de propiedad a las necesidades colectivas, de 
¿ES POSIBLE PROGRAMAR TEMPORALMENTE LA EJECUCIÓN DE LAS OBRAS...

forma que surge en ese derecho, antaño absoluto, una perspectiva social, porque se subordinan los derechos inherentes al dominio a los fines e intereses de la sociedad.»

\section{La Ley de Disciplina Urbanística de la CAIB (LDU)}

A) A continuación, debemos traer a colación —en punto a fundamentación jurídica de la modificación que se pretende- algunos preceptos de la Ley de Disciplina Urbanística de la CAIB, puesto que el Consell Consultiu sostiene que la programación de licencias vulnera lo dispuesto en los artículos 1,7 y 8 de la LDU, por lo cual no respeta los principios de legalidad y de jerarquía normativa. De estos preceptos extrae el citado organismo la conclusión de las licencias de edificación han de tener una efectividad inmediata a partir de su otorgamiento, eficacia que quedaría alterada por la entrada en vigor de la discutida norma y su «temporalización» en la efectividad de las licencias de edificación (Consideraciones Jurídicas $2 .^{\mathrm{a}}, 3 .^{\mathrm{a}}$ y $6 .^{\mathrm{a}}$ ).

B) Con el debido respeto a la opinión del alto órgano consultivo, discrepo de la tesis que se acaba de citar, ya que, a mi juicio, la LDU no conduce en absoluto a esa conclusión:

B. 1 El artículo 1 de la misma ${ }^{11}$ no impide realmente la programación temporal de la ejecución de las licencias. En efecto, la medida que se pretende no disminuye las posibilidades de adquisición de facultades urbanísticas, ya que no supone merma o reducción en lo que respecta al contenido de los derechos de aprovechamiento urbanístico de los particulares: como ya se ha dicho, el quantum de estos derechos continúa siendo exactamente el mismo, ya que la edificabilidad (usos, intensidades, tipologías) que les atribuye el Plan y les reconoce la licencia no varía en absoluto, con o sin programación. Lo único que se altera en realidad es el ritmo temporal de ejercicio del derecho a edificar por parte de los titulares de la licencia. El argumento se confirma si se observa en que el inciso final del precepto remite a los establecido no sólo en las leyes sino también «en los planes» y el resto de normativa urbanística.

B.2 No obstante lo anterior, la propia Ley de Disciplina Urbanística contiene otras reglas que podrían entenderse contrarias a la posibilidad

\footnotetext{
11 Art. 1 LDU: «La licencia es el acto administrativo mediante el cual adquieren efectividad las posibilidades de... edificación... aprovechamiento o uso relativo a un suelo o inmueble determinado, previa concreción de lo establecido al respecto en las leyes, los planes de ordenación y el resto de normativa urbanistica.»
} 
que estamos analizando de programar la ejecución de las licencias. Me refiero en concreto al artículo 7.3 de la Ley, el cual prevé la hipótesis de que el particular presente el proyecto básico y el proyecto de ejecución no de modo simultáneo sino separados en el tiempo y las consecuencias de ello. El precepto señala en concreto:

"Cuando la licencia de obras se haya solicitado y obtenido mediante la presentación de un proyecto básico, será preceptiva, en el plazo máximo de seis meses desde la concesión de aquélla, la presentación al Ayuntamiento del proyecto de ejecución ajustado a las determinaciones de aquél. El Ayuntamiento dispondrá de un mes para comprobar la adecuación del proyecto de ejecución con el proyecto básico. Transcurrido este plazo sin que el Ayuntamiento notifique al interesado resolución en contra, se podrán iniciar las obras. Esta fecha será la que fijará el inicio del plazo de ejecución fijada en la licencia.»

Como vemos, la Ley establece aquí un sistema en el que primero se presenta el proyecto básico acompañando a la solicitud de la licencia, seguidamente se concede ésta y, a continuación, el particular debe presentar el proyecto de ejecución en el plazo máximo de seis meses. El Ayuntamiento tiene entonces un mes para contestar sobre si el proyecto de ejecución se adecua al proyecto básico. Llegados a este punto, pueden darse tres hipótesis en la práctica, aunque la Ley sólo explicita la primera de ellas:

- que la Administración no conteste en el plazo del mes, con lo que se producirá un supuesto de silencio positivo y «se podrán iniciar las obras», entendiéndose este momento como el de inicio del plazo de ejecución de las obras;

- que el Ayuntamiento resuelva afirmativamente dentro del plazo del mes, con lo cual también se podrán iniciar las obras a partir del momento en que se notifique dicha resolución, entendiéndose este momento como el de inicio del plazo de ejecución de las obras;

- que el Ayuntamiento resuelva negativamente («resolución en contra») dentro del plazo del mes, con lo que debemos entender que ya no se podrán iniciar las obras (interpretando a sensu contrario la regla legal citada), sino que el particular tendrá que subsanar las deficiencias que se le señalen y deberá producirse una resolución final de conformidad por parte del Ayuntamiento, cuya notificación permitirá iniciar las obras, entendiéndose este momento como el de inicio del plazo de ejecución de las obras.

Este artículo 7 LDU parece ser para el Consell Consultiu el principal obstáculo para admitir la validez del sistema de programación de licen- 
¿ES POSIBLE PROGRAMAR TEMPORALMENTE LA EJECUCIÓN DE LAS OBRAS...

cias ${ }^{12}$. Ante esta argumentación, conviene oponer varias consideraciones:

a) Aunque a primera vista este precepto hace más dificil la posibilidad de programar la ejecución de las licencias que se proponen los Ayuntamientos citados, no creo que el mismo sea un obstáculo insuperable para ello. De entrada, porque la redacción del artículo 7.3 LDU está partiendo de un supuesto de hecho muy distinto al que aquí nos ocupa y está recogiendo una praxis tradicional (la posibilidad de iniciar inmediatamente las obras), pero evidentemente no contempló la hipótesis de ejecución diferida de las obras, por lo que no se desprende del mismo la voluntad de prohibirla. En efecto, el citado precepto estaba pensado sólo en el supuesto de la hipótesis del silencio administrativo, y por ello permite la iniciación inmediata de las obras. El artículo 7.3 LDU dice ciertamente que transcurrido el plazo del mes de que dispone el Ayuntamiento para revisar el proyecto de ejecución sin que se dicte y se notifique resolución expresa, «se podrán iniciar las obras» y que, consecuentemente, «esta fecha será la que fijará el inicio del plazo de ejecución fijado en la licencia». Pero, ¿por qué esta afirmación? Pues, porque si el Ayuntamiento no contesta en ese plazo, se produce un silencio administrativo positivo por el mero transcurso del mismo. Por lo tanto, la LDU está refiriendo esta solución al supuesto específico de que se produzca el acto presunto o por silencio administrativo, pero nada más; en mi opinión, no cabe extender mecánicamente esta solución a los casos en los que no haya silencio administrativo sino resolución expresa, tal como hace el Consell Consultiu, dada la acotación inequívoca de la parte final del artículo 7.3 a la hipótesis de que exista acto presunto.

Por supuesto, entiendo que en caso de que exista silencio administrativo se podrán iniciar las obras inmediatamente después de producido el silencio y sin que se aplique la programación temporal a la licencia así obtenida ( ¿de qué otra forma podría hacerse, si la Administración no ha dicho nada?). Pero, reparemos en que la programación temporal de licencias no ha de referirse en absoluto al supuesto de las obtenidas por silencio, sino en todo caso a las otorgadas por resolución expresa. En consecuencia, con esta interpretación —que reserva la programación tempo-

\footnotetext{
${ }^{12}$ La Consideración Jurídica $6{ }^{\mathrm{a}}$ del dictamen dice textualmente que la norma proyectada olvida el principio de legalidad y la reserva de ley, «habida cuenta muy especialmente de que, según se ha puesto de relieve anteriormente, el artículo 7 de la $L D U$ previene que la fijación "del inicio del plazo de ejecución" de la licencia viene marcado especificamente por tal precepto, lo que implica que, en atención al rango que le corresponde en la jerarquía normativa, no puede dicha prescripción ser desconocida o alterada por reglas de inferior categoria, cuales son los planes de ordenación urbanistica».
} 
ral sólo para el caso de que la licencia sea expresa y no por silencio- la modificación pretendida por los Ayuntamientos citados sería perfectamente compatible con el artículo 7.3 de la LDU. No hay, pues, contradicción entre este precepto legal y la norma que se pretende introducir en el Plan.

b) La segunda consideración consiste en que la Ley admite implícitamente un supuesto de ejecución no inmediata de obras, que es el de la «resolución en contra» del Ayuntamiento al proyecto de ejecución. Esta hipótesis creo que ofrece base suficiente para entender que la ejecución «inmediata» de obras tras la licencia no es consustancial al sistema establecido por la Ley, sino que es un elemento accesorio del mismo, consecuencia del único supuesto de hecho que contempla expresamente la Ley (la hipótesis de silencio), por lo que creo que el Plan puede válidamente alterar este elemento de modo justificado, al tratarse de un elemento no sustancial. Dicho con otras palabras: en mi opinión, la LDU no concede en el artículo 7.3 un derecho subjetivo intocable a iniciar las obras de modo inmediato a la resolución del Ayuntamiento sobre el proyecto de ejecución — salvo en el caso del silencio administrativo-; de ahí que considere legalmente posible que el Plan de urbanismo pueda establecer la posibilidad de un sistema de ejecución diferida de las obras.

c) Tercero, porque el citado precepto debe ser interpretado de modo sistemático como una pieza más del conjunto de material normativo de que disponemos respecto al tema que nos ocupa. $\mathrm{Y}$ de ese conjunto-que estamos examinando- se desprende la posibilidad de fijar tanto plazos máximos como mínimos al deber de edificar.

Así interpretado el artículo 7.3, entiendo que es posible que, una vez presentado un proyecto básico, la licencia que se otorgue programe la ejecución de las obras en los términos de la modificación que proponen los Ayuntamientos citados, con lo que el proyecto de ejecución deberá recoger y aceptar las fechas de ejecución de obras señaladas por la Administración. Si no se hace así, la resolución que ha de dictar el Ayuntamiento en el plazo de un mes podrá ser «en contra» del proyecto de ejecución presentado, al no adaptarse éste al calendario temporal fijado en la licencia concedida y, en definitiva, al no adaptarse al propio planeamiento, en cuanto éste permita la programación de la licencia. Y si hay «resolución en contra», las obras no podrán iniciarse, de acuerdo con el artículo 7.3 LDU, interpretado a sensu contrario como ya se ha dicho.

En cambio, si la licencia fija fechas para la realización de obras y el proyecto de ejecución las recoge y acepta, la resolución del Ayuntamien- 
to tendrá que ser favorable al mismo, y habrá que estar entonces a las fechas señaladas en la licencia para determinar el inicio del plazo de ejecución de la misma.

B.3 Por último, el articulo 8 de la $L D U^{13}$ tampoco me parece obstáculo para admitir la legalidad de la modificación pretendida. La razón de ello es que los plazos a que se refiere el artículo 8.1 son aquellos cuyo transcurso permite declarar la caducidad de la licencia otorgada, estableciendo así un mecanismo de reacción administrativa contra la pasividad de su titular o contra la obtención de licencias para especular con ellas. Esa es la ratio de dicho precepto. Pero, como es lógico, la existencia de estos plazos — que se mantienen en la modificación debatida - no impide la existencia de otros que sean compatibles con ellos y que estén justificados en razones distintas. Eso es lo que ocurre en el caso que analizamos: la existencia de un plazo máximo para iniciar las obras y de un plazo máximo para terminarlas no impide en absoluto que se imponga además un plazo mínimo para iniciar las obras, dado que éste es perfectamente compatible con aquéllos (aunque ello obligará a computar el plazo máximo de terminación no desde el momento en que se otorgó la licencia sino en el momento en que se pudieron iniciar las obras legalmente). En consecuencia, la ratio de la modificación ya no es posibilitar la declaración de la caducidad de las licencias - como ocurre con el art. 8 LDU-, sino hacer posible un desarrollo urbanístico gradual y sostenible.

B.4 En conclusión, el plazo mínimo para iniciar las obras es un plazo nuevo, distinto de los plazos previstos en la LDU, fundamentado en otras razones y perfectamente compatible con ellos. Así las cosas, no me parece que haya contradicción entre la modificación pretendida y los citados preceptos legales.

\section{Sobre el carácter reglado de las licencias y el principio de seguridad jurídica}

A) Otro de los argumentos centrales del Consell Consultiu para fundamentar su decisión consiste en considerar que la modificación propuesta vulnera el carácter reglado de las licencias urbanísticas, así como el principio de seguridad jurídica ${ }^{14}$.

\footnotetext{
13 Art. 8 LDU: «Toda licencia, de acuerdo con la normativa urbanística municipal, deberá prever un plazo para comenzar las obras proyectadas y otro para acabarlas»; y que «transcurridos cualquiera de los dos plazos, el Ayuntamiento iniciará el expediente de caducidad de la licencia otorgada.»

${ }_{14}$ Así, en la Consideración Jurídica $4 .^{\text {a }}$ del dictamen se recuerda la jurisprudencia que afirma la naturaleza reglada de estas licencias, añadiendo que no cabe pensar en la inserción de condiciona-
} 
B) Nadie pone en duda el carácter reglado de las licencias urbanísticas. Carácter reglado que significa efectivamente que el otorgamiento de la licencia constituye un «acto debido» al que la Administración no puede negarse si la licencia solicitada cumple todos los requisitos legales (los previstos en el ordenamiento jurídico), debiendo ser otorgada necesariamente en ese caso y debiendo ser denegada en caso contrario. Por esa razón, la Administración no dispone de un margen de libertad o discrecionalidad para conceder o no la licencia por razones de oportunidad, no siendo por ello admisible la imposición de condiciones o requisitos que no estén previstos por las normas, dado en definitiva el principio de tipicidad del contenido de los actos administrativos (art. 53.2 de la Ley de Procedimiento Administrativo Común). Así las cosas, las únicas condiciones admitidas por la jurisprudencia son en efecto las conditiones iuris. Hasta aquí, el razonamiento del Consell Consultiu resulta impecable.

Pero lo que no cae en la cuenta esta argumentación es que aquí no se trata de enjuiciar si una licencia determinada puede imponer una condición no prevista en las normas (en concreto, la programación temporal en la ejecución de la licencia), sino que se trata de analizar si una norma reglamentaria como es el Plan General puede introducir o no válidamente ese condicionamiento temporal. Dicho con otras palabras: no estamos enjuiciando la legalidad de un acto administrativo singular - como es una licencia-, sino de una disposición de carácter general que incorpora per se aquel condicionamiento. $\mathrm{Y}$, en consecuencia, el argumento empleado - que sería correcto cuando se trate de analizar la validez de una licencia determinada - es inadecuado para contrastar la licitud de una norma como es un plan urbanístico. En este caso habrá que averiguar si la norma en cuestión tiene el rango y la fuerza suficiente para introducir la medida de que se trate, pero no es correcto desplazar el enjuiciamiento de la cuestión al nivel de los actos de aplicación. Eso es lo que hemos intentado hacer precisamente en este trabajo: justificar que los planes urbanísticos pueden introducir válidamente este tipo de condicionamientos.

C) Desde el momento en que el requisito o condicionamiento de que se trate se incorpora a la norma, al ordenamiento jurídico, no existe contradicción con el carácter reglado del acto de aplicación - la licencia-, ya que éste se adaptará precisamente a lo establecido en la norma. En efecto, desde el momento en que la programación temporal de las licencias se impone desde el Plan General, el otorgamiento de cualquier licen-

mientos que impliquen la inefectividad de las mismas o dilaten dicha efectividad, pues las únicas condiciones admisibles son las llamadas conditiones iuris, es decir, aquellos condicionamientos derivados del ordenamiento jurídico que evitan la denegación de la licencia. 
cia deberá recoger necesariamente ese requisito, dado justamente su carácter reglado. Es decir, que en ese caso, la programación temporal de una licencia determinada no sólo no vulnerará su carácter reglado sino que justamente lo cumplirá y sería ilegal la licencia que no lo hiciera así.

D) El dictamen que comentamos señala que el sistema de programación de licencias atenta además contra el principio de seguridad jurídica ${ }^{15}$.

Pues bien, de la misma manera que antes, la regla debatida no vulnera el principio de seguridad jurídica desde el momento en que se incorpora a una norma - pasando a formar parte del ordenamiento jurídico- y que se trata de una regla clara y determinada con precisión, sin dejar márgenes de discrecionalidad en su aplicación a la actuación administrativa. Habría vulneración de aquel principio si la regla debatida no estuviera establecida normativamente, o si no estableciera de modo preciso los criterios para programar las licencias - como el relativo al orden de ejecución de unas respecto a otras - o bien si otorgara a la Administración la potestad de fijar libremente el momento de la realización de las obras. Pero ya hemos visto que no es así, ya que la ejecución de la licencia es cierta tanto en cuanto a su contenido (certus an) como en cuanto al momento temporal (certus quando) ${ }^{16}$.

E) En conclusión, en mi opinión no hay contradicción en absoluto de la modificación normativa pretendida con el carácter reglado de las licencias urbanísticas, ni con el principio de seguridad jurídica.

15 «No es por tanto fórmula adecuada, ajustada a Derecho, la ofrecida por dicho artículo 2.07, por cuanto al disociar concesión de licencia de edificación y su efectividad, de tal modo que su otorgamiento vaya acompañado por un incertidumbre en la realización, se corre el riesgo de atentar al principio constitucional de la seguridad jurídica» (Cons. Jurídica 6. ${ }^{a}$ ).

${ }^{16}$ El propio dictamen del Consell Consultiu viene a reconocer la adecuación al principio de seguridad jurídica, de modo contradictorio con el párrafo antes transcrito, cuando afirma que «sólo mediante una Ley reformadora de la de Disciplina Urbanistica habrá lugar a que se introdujera en el Ordenamiento aplicable la innovación reflejada en la controvertida norma» (Cons. Jurídica 6. ${ }^{2}$ ): $\mathrm{si}$ la regla en cuestión vulnera el citado principio, ello también sucederá aunque esté contenida en una norma con rango de ley. Como vemos, eso no es así en realidad, ya que no se produce ninguna incertidumbre en la ejecución de la licencia, dado que al otorgarla se señala con precisión el momento temporal en el que se pueden comenzar las obras. ¿Dónde está entonces la «incertidumbre en la realización» de la licencia de que habla el dictamen del órgano consultivo? Llegado el momento en que puedan válidamente iniciarse las obras, éstas empezarán o no simplemente por decisión de su titular, y no de la Administración. 


\section{La programación de la actividad urbanística}

La última fundamentación legal de la medida que se pretende implantar por los Ayuntamientos citados deriva también de las previsiones de la legislación vigente con referencia a la programación de la actividad urbanística. En efecto, el artículo 41 del Reglamento de Planeamiento Urbanístico describe el Programa de Actuación del Plan General señalando como contenido del mismo fijar «los objetivos, directrices y estrategia de su desarrollo a largo plazo para todo el territorio comprendido en su ámbito», así como «los plazos a que han de ajustarse las actuaciones previstas, en su caso, para completar la urbanización en suelo urbano o para realizar operaciones de reforma interior en este tipo de suelo».

El Programa de Actuación es entonces el documento en el que se recogen las previsiones del Plan para la efectiva realización en el tiempo de sus determinaciones. De esta manera, la Ley del Suelo configura el planeamiento no sólo como una ordenación estática del espacio físico, sino que integra también el factor temporal como uno de los elementos esenciales del sistema de planeamiento.

Pues bien, aunque los Programas de Actuación suelan referirse sólo a la ejecución de las obras de urbanización, nada impide que puedan englobar también la actividad edificatoria. Así permite entenderlo especialmente la habilitación del artículo 41 del Reglamento de Planeamiento para que el Programa señale «los objetivos, directrices y estrategia» del desarrollo del Plan: estos objetivos y sobre todo esta estrategia de desarrollo apelan a ejecución o despliegue del Plan en el tiempo, sin que los mismos tengan que limitarse forzosamente a la mera labor urbanizadora: ¿qué significa en otro caso la palabra estrategia?

A mi juicio, este tipo de programación de la edificación que se pretende por los Ayuntamientos de Calviá e Ibiza no viene impedida o prohibida por la Ley sobre el Régimen del Suelo y Valoraciones de 1998. Aunque esta norma es de signo claramente «liberalizador», las innovaciones que introduce al respecto se refieren fundamentalmente a los procesos urbanizadores y no a los edificatorios. En este sentido hay que interpretar el nuevo «derecho a promover la transformación» del suelo urbanizable que consagran los artículos 15 y 16: un derecho que consiste en instar de la Administración la aprobación del correspondiente planeamiento de desarrollo (art. 15), que puede ejercerse desde el momento en que el planeamiento general delimite sus ámbitos o establezca las condiciones para su desarrollo (art. 16). Pero una vez el suelo ya está urbanizado (o es urbano), la LS/98 no hace desaparecer la programación, ya que sigue contem- 
plando como uno de los deberes de los propietarios el de edificar los solares en los plazos que establezca el planeamiento (art 14, antes comentado). Pensemos al respecto que la programación se ha aplicado hasta ahora sin ser cuestionada en cuanto a la actividad urbanizadora, y a esa idea responde tanto el Programa de Actuación del Plan General como los planes de etapas del Plan Parcial. ¿Por qué no admitir entonces la misma posibilidad en cuanto a la actividad edificatoria?

\section{CONCLUSIÓN}

Por todo lo que se ha expuesto, considero que la modificación del PGOU que pretenden introducir los Ayuntamientos de Calviá e Ibiza en el mismo no es contraria a Derecho y encuentra fundamento material más que suficiente en la normativa urbanística en vigor, tal como se ha expuesto hasta aquí.

En definitiva, el fundamento último de las medidas que se pretende adoptar se encuentra en el artículo 45.2 de la Constitución, que ordena a los poderes públicos velar «por la utilización racional de todos los recursos naturales, con el fin de proteger y mejorar la calidad de vida y defender y restaurar el medio ambiente». A estas alturas nadie discute que el suelo es un recurso natural, y en la Comunidad Autónoma de las Islas Baleares es además un recurso sumamente escaso; si a ello le unimos la carestía de otros recursos como el agua, la legitimidad de las medidas que comentamos se ve reforzada. 
REAL-2001, núm. 285. BLASCO ESTEVE, AVELINO. ¿ES POSIBLE PROGRAMAR TEMPORALMENTE...

REAL-2001, núm. 285. BLASCO ESTEVE, AVELINO. ¿ES POSIBLE PROGRAMAR TEMPORALMENTE... 